\title{
Higher education for sustainable development: Research-based learning (the case of the Ural State University of Economics)
}

\author{
Irina Pirozhkova* \\ Ural State University of Economics, 8 Marta Str., 62, 620144 Ekaterinburg, Russia
}

\begin{abstract}
Development of higher education requires academics to search for new forms and approaches to teaching. Research-based teaching and learning is a sound approach that meets the requirements of the state for attraction of your people to scientific and research activities. Researchbased learning is a process of knowledge acquisition with the help of analysing, experimenting and interpretation of data with the help scientific methods of analysis. A serious of lessons designed with the help of research-based learning principles have been integrated into the discipline Foreign language. As a result, 18 research papers have been written by students, 15 of them have been published. A survey has been conducted to reveal the students' attitude to and interest in research work.
\end{abstract}

\section{Introduction}

The role of science in today's rapidly developing world is huge. According to UNESCO "Science generates solutions for everyday life and helps us to answer the great mysteries of the universe. In other words, science is one of the most important channels of knowledge. It has a specific role, as well as a variety of functions for the benefit of our society: creating new knowledge, improving education, and increasing the quality of our lives. $<\ldots>$ To face sustainable development challenges, governments and citizens alike must understand the language of science and must become scientifically literate".

Based on these ideas governments of many countries implement various programs and plans to promote scientific activity. For instance, in Russia there is a Program for fundamental scientific research that outlines the main research areas for the next 10 years. It covers all scientific fields and aims at the increase of the relevance of research for the economic development of the country. Besides, the National project "Science" was launched in 2018 to help Russia be among the top five countries in the scientific areas relevant for the country and to make Russia attractive for researchers. All these projects emphasize the role of young people in the research sphere. It means that involvement into scientific work should start at quite an early age: the basis of research work could be presented and explained at school, while at university it is important to involve students into research projects. In this paper we discuss the variants of promotion of scientific awareness among students in the Ural State University of Economics. The goal of this study

* Corresponding author: irene22@live.ru 
is to carry out an experimental integration of research-based learning into English language classes and to provide academics with the ideas for research-based learning implementation. To reach this goal we have done the following: 1) examined the recent publications on the problems of research-based learning and provided a methodology for its integration in English language classes; 2) described the activities of the university and particularly Department of Business Foreign Language that may increase the students' interest in research work; 3) designed and tested a serious of lessons using research-based learning principles; 4) conducted a survey among the students to find out their attitude and experience of scientific work; 5) made a list of advantages of research-based learning in class and in independent work of students.

\section{Materials and methods}

\subsection{Research Methods}

To reach the goals of the study, the following methods have been used: general scientific methods of analysis, comparison, generalization, description and interpretation allowed to provide an approach to teaching on the basis of the previous experience; empirical methods of pedagogical observation, experiment and methodology design helped to analyze the current problems students face in their research activity and find solutions. A survey among students was held to find out their understanding of the concept of scientific work and involvement in research projects.

\subsection{Literature review}

Today there are various methods of teaching that make students the active participants of learning rather than the passive observers. One of such methods is research-based learning which appeared in the 1990-s and aims to replace traditional classroom practice of knowledge transfer from teacher to students, known as traditional or lecture-based approach. Initially research was referred to teachers only, who were focused on their own research work rather than on development of students' research skills. There are various definitions of the concept of research-based learning: "research-based learning refers to a student learning process accomplished through inquiry and discovery to advance knowledge within a research-based curriculum" [1]; "research-based learning is a learning model which is associated with such activities as analyzing, synthesizing, and evaluating, and enables learners and lecturers to improve their assimilation and application of knowledge [2]; "research based learning is the integration of the theoretical knowledge base or theoretical knowing with the use of appropriate data collection and analysis procedures to examine, verify or study a phenomenon or occurrence" [3].

Research-based learning has been applied in various forms to teaching different subjects. For instance, the opportunities of this approach have been identified in the program for future teachers [4], in some disciplines for engineering students [5]; in teaching Entrepreneurship and Innovation undergraduate courses [6]; in the program of biotechnology [7]; in Geotechnics course [8]; in human psychology classes [9], etc. All the authors agree that implementation of research-based learning results in a higher commitment level and improved research skills of students; academic performance is improved together with the higher motivation to learning in general. Besides, it has been shown that research-based learning can be used in online study [10], or it may be combined with digital technologies [11]. The articles underline that though this work may be 
challenging for students, as they need to combine digital and research skills, it proved to be highly engaging and interesting for the students.

At the same time, it is important to provide teachers with the necessary training to be able to implement research-based learning. It is stressed that higher education is in need for further professional development of teachers to be able to build a sustainable researchbased educational system [12].

Most scholars agree that research-based learning "should occur early in the academic experience, be practiced in more than just one undergraduate course, and be done within a research-directed component of the course in order to actively apply skills" [1].

It is a well-known fact that research in most Russian universities begins in the second or third year of undergraduate programs. Students perform independent research and present its results in a course paper. However, students often complain of lack of information on how a research should be done and in what way its results should be described. To compensate for the lack of knowledge it is beneficial to integrate the research-based teaching and learning principles in foreign language teaching. Our research hypothesis is that research-based practice in English language teaching will acquaint students with the basis of research design, motivate them for deeper study of their major and provide them with the necessary hard and soft skills (application of research methods to the study of professional problems, analysis of professional literature, presentation, academic speaking, etc.).

\section{Results and discussion}

\subsection{Students' research activities}

First, it is necessary to give a brief description of the work of the Department of Business Foreign Language (Ural State University of Economics) in the field of development of the students' research skills. There are two main events held by the department: 1) a contest of scientific research works of students "Socio-cultural relations as the foundation for successful economic cooperation" within the Eurasian Economic Youth Forum. This contest is held annually and attracts students from different universities in Russia and abroad who present a 20-page written study. It has three main stages: selection - when experts choose the best 10 papers from all the studies submitted (in this case the written text is evaluated), presentation - when the selected students present research results in front of the experts and the audience (here the academic presentation skills are assessed), publication - when the winners write short articles to be published in the conference proceedings; 2) a contest of scientific papers among the students of the Ural state university of economics "Russia in the global world. Challenges of the XXI century". Students present the results of their independent research in the form of a 5-page article on one of the following problems: inequality, globalization, digital transformation, foreign economy, marketing, effective management and HR management. The contest usually attracts students from the Institute of Management and Information Technologies, as the topics are close to their core subjects. Both contests are held in English and are organized in a form of a conference. Such design allows students to reach the final stage of their research activity - presentation of research results and publication of the article.

The experience of these contests gave an idea to involve all students from the academic group in one of them (the second contest has been chosen due to its simpler structure) and compare the interest in research activities and the knowledge of research design among the students who took part in the contest (the experimental group) and those who did not participate in it (the control group). 


\subsection{Research-based learning (the case of Ural State University of Economics)}

Research is a part of all undergraduate programs in Russian universities in the form of the course papers and the graduation work. In most cases students are supervised by the academics, they get advice and assistance. However, many students complain that they do not have enough basic information to do independent research and they are ashamed to ask their supervisor such trivial questions (for instance, about the research methods, the plan of the chapter, the list of references, etc.). We fully agree that it is important to incorporate research activities in different courses and start teaching students the main principles of research work from the first year at university. Research-based learning is a good way to do it, if it is used, there is no need to implement new courses into the curriculum. In this study we describe the experience of implementation of research-based learning in the discipline "Foreign language" in the group of $2^{\text {nd }}$ year students majoring in Management. It should be noted, that the textbook includes some exercises to develop research skills, but they are too simplified and do not contain the factual information on how to plan and fulfill research. So, we offered the students the following classroom activities:

- Science lead in - students were explained the structure of a scientific paper, research methods, goals, hypothesis and resources for the study on the basis of an abridged article in English. As far as the resources are concerned, we believe it is important to explain the students which sources of information are reliable and where we can find them. Ten years of experience of being scientific supervisor have shown that students often use such unreliable sources as blog posts, newspaper articles, Wikipedia entries, etc. as the theoretical foundation for research. However, it is advisable to refer to the Web of Science database, elibrary, cyberleninka, researchgate, etc. To consolidate the new information, a written task was given to choose a topic for their research and to make an overview of three articles relevant for it. At the end of the class the papers were collected and assessed. Additionally, students were informed about the contest of research papers held by the Department and received the home assignment to adjust the topic of their research to the areas of the contest and to write the introduction and theoretical part of the paper.

- I am a researcher - on the example of analysis of advertisements translation, students were explained the basis of the main (experimental or analytical) part of research. The task that followed was to work out the plan of the main part for their own study and to organize a group discussion of this plan (students were divided into small groups). After discussion the teacher had an individual conversation with each student in order to answer their questions and solve the problems they faced. The home assignment was to do an independent research and to describe and analyze its results.

- Formatting requirements - it appears to be difficult for the students to comprehend the Call for Papers (or Information letters) and to follow all the requirements. So, during this class we analyzed and explained every paragraph in the Information Letter of the contest "Russia in the global world. Challenges of the XXI century". Special attention was paid to authenticity (i.e. the rate of unauthorized borrowings) and ways to write an original paper; deadlines (submission deadline, presentation deadline, etc.); formatting (page layout, font, spacing, etc.); and references. The home assignment was to format the article and submit it to the contest organizers.

Some features of this kind of research-based learning must be mentioned: 18 students took part in this work; the teaching and learning was in English; the papers were written in English; all discussion was held primarily in English with the seldom use of Russian in the most problematic areas; the level of English in the group is B1-B2. Classroom work took 5 academic hours, which is not too much and it did not interfere with the main program of the discipline. 15 papers out of 18 were selected for the second part of the contest, 6 students won the awards for their works. So, this is an example of how research-based learning 
might be incorporated in any curriculum. At the end of this work we made a survey, the results of which are shown below.

\subsection{Survey: procedure and discussion}

At the end of our experimental research-based teaching we made a survey to find out the students' attitude to the process and to research work in general, to reveal their benefits. The survey was held in two groups (from 16 to 18 students in each) of the program Management, the $2^{\text {nd }}$ year. The answers to the questions are shown in Table 1.

Table 1. Students' attitude to research activities

\begin{tabular}{|l|c|c|c|c|}
\hline \multicolumn{1}{|c|}{ Question } & \multicolumn{2}{c|}{ Experimental group (\%) } & \multicolumn{2}{c|}{ Control group (\%) } \\
\cline { 2 - 5 } & Yes & No & Yes & No \\
\hline Did you take part in scientific events? & 100 & 0 & 64 & 36 \\
\hline Are you interested in research work? & 86 & 14 & 73 & 27 \\
\hline Do you know the principles of scientific research? & 71 & 28 & 40 & 60 \\
\hline Should students do research? & $\begin{array}{c}76 \text { (only if the } \\
\text { student wants } \\
24)\end{array}$ & 0 & 55 & 45 \\
\hline $\begin{array}{l}\text { Do you think that writing a course paper is a } \\
\text { research work? }\end{array}$ & 86 & 14 & 64 & 36 \\
\hline
\end{tabular}

Thus, we see that the majority of students in both groups have some experience of scientific work and they are interested in it. As for the main principles of scientific research, the experimental group shows a better tendency $(71 \%$ of students have the necessary knowledge), while in the control group only $40 \%$ of respondents admit their acquaintance with them. The question about the necessity for a student to do research revealed the difference: in the experimental group all students admit that this work is important, however $24 \%$ underline that it should not be obligatory; in the control group only $55 \%$ of students think that research work is important for them.

There were some additional questions that help to provide a clearer idea. In the control group the reasons for not taking part in scientific events are lack of time, interest and opportunities. In other words, some students do not know where they can develop their research skills. Some of them said that they prefer practice to theory, however, research is not at all pure theory and this is shown very well with the help of research-based learning. Speaking about the importance of science for young specialists, the majority of students in both groups believe that it is very important both for professional (deeper knowledge of the subject, acquaintance with new inventions and trends) and soft skills (background knowledge, independence, self-development, presentation skills, team work). The control group named experiments and analysis as the most interesting scientific activities, while the range of answers in the experimental group was much wider: analysis and interpretation of the theory; the process of scientific paper writing; analysis of research results; presentation of research to the audience; academic discussion.

In general we may say that with the increase of knowledge about research and scientific work, the interest to this activity rises. The students from experimental group mentioned that the stereotype that research work is "only for men of genius" was broken and they realized that they could also be involved in this sphere. Thus, our hypothesis is verified. 


\section{Conclusion}

The main advantages of the research-based teaching and learning offered in this study are the following: 1) Completeness - students try all stages of research: literature review, research planning, results analysis, presentation and publication; 2) Shortness - it requires 5 academic hours and does not seriously interfere with the main program of the discipline; 3 ) Guided independence - students are supervised in all stages, they are inspired to ask all questions concerning research, even if they seem to them "silly"; 4) Combination of skills professional skills (the research problem is connected with the major), language skills (reading, writing, speaking), scientific skills (research planning and performance, academic presentation), soft skills (independence, critical and analytical thinking, resourcefulness, etc.).

However there are certain limitations of this research. First of all, the sample is quite small, so the results of the survey cannot be referred to all students. Secondly, the proposed classroom activities were tested in English language classes, so there might be some adaptation necessary when teaching other disciplines. Finally, it is not always possible to find a conference for students to present their research results, but there are many conference proceedings for students to publish the papers and academics may help students.

Integration of research activities into teaching different subjects may have the following benefits: 1) for the students - development of crucial professional and general competences and better understanding of science and professional subjects which motivates them for successful learning; 2) for the academics - better students' performance and their involvement into classroom work; 3) for university - publications of students in journals and conference proceedings.

\section{References}

1. J.P. Labeouf, Bollinger-Rosado Teaching \& Learning Effectiveness Symposium Proceedings (2016)

2. T. Susiani, M. Salimi, R. Hidayah, SHS Web of Conferences, 42 (2018)

3. V. Arora, P. Saxena, N. Gangwar, Higher Education Faculty Career Orientation and Advancement (2017)

4. P. Jiraro, A. Phothisuk, N. Suwanaruji, P. Klosawasdi, S. Jiraro, St. Theresa, Journal of Humanities and Social Sciences, 6(2), 194 (2020)

5. A.M.O. Hernandez, E.C. Tapia, A.V. Martinez, F.A.U. Landa, V.V. Lopez, L.E.V. Guerrero, IEEE global engineering education conference proceedings, 1451 (2020)

6. M.H. Camacho, K. Chiluiza, M. Valcke, Studies in higher education, 46(4), 690 (2021)

7. K. Mayolo-Deloisa, A.M. Ramos-de-la-Pena, O. Aguilar, IJIDEM, 13, 4 (2019)

8. M. Pantazidou, K. Kandris, iJEP, 10, 1 (2020)

9. É. M. Granjeiro Adv Physiol Educ, 43, 553 (2019)

10. T.A. Roman, M. Callison, R.D. Myers, A.H. Berry, TECHTRENDS, 64(4), 591 (2020)

11. V. I. Marín, Australasian Journal of Educational Technology, 36(1), 1 (2020)

12. U. Bergmark, Professional Development in Education, 1 (2020) 